\title{
Treatment adherence in hemophilia
}

This article was published in the following Dove Press journal:

Patient Preference and Adherence

27 September 2017

Number of times this article has been viewed

\author{
Courtney D Thornburg' \\ Natalie A Duncan ${ }^{2}$ \\ 'Hemophilia and Thrombosis \\ Treatment Center, Rady Children's \\ Hospital, San Diego, CA, ${ }^{2}$ Indiana \\ Hemophilia and Thrombosis Center, \\ Indianapolis, IN, USA
}

\begin{abstract}
Prophylactic clotting-factor regimens reduce the occurrence of bleeding episodes and maintain joint health in individuals with moderate and severe hemophilia. However, these outcomes are only achieved with adherence to prescribed prophylaxis regimens. There are several types of barriers to adherence related to key patient, condition, treatment, health-care system, and/or socioeconomic variables. Notably, health-care professionals may not prescribe prophylaxis if they perceive that a patient will be nonadherent. Prophylactic treatment strategies should be developed with the patient and family, focused on individualized treatment goals. Personalized strategies are needed to reinforce the importance of and encourage confidence in administering the regular infusions required for prophylactic therapy. These strategies may include verbal and written information delivered by health-care professionals, peers, and interactive media. The advent of extended half-life clotting factors requiring less frequent infusion may improve adherence.
\end{abstract}

Keywords: hemophilia, prophylaxis, adherence, VERITAS-Pro

\section{Introduction}

Hemophilia A and B are rare inherited bleeding disorders caused by deficiency of coagulation factor VIII (FVIII) and factor IX (FIX), respectively. ${ }^{1}$ These disorders are characterized by recurrent bleeding episodes, primarily into the joints and muscles. ${ }^{2}$ Over time, repeated joint bleeding damages the cartilage and bone, which ultimately leads to crippling arthropathy. ${ }^{1}$

Hemophilia is typically treated with coagulation-factor replacement administered either prophylactically, ie, to prevent bleeding episodes, or episodically (on-demand when bleeding occurs). ${ }^{3}$ Prophylaxis is the preferred treatment regimen for patients with severe hemophilia (generally defined as $<1 \%$ baseline clotting-factor activity), as it significantly reduces the frequency of total and joint bleeding events and substantially reduces the frequency of hemophilic arthropathy compared with episodic treatment. ${ }^{4-11}$ Results from magnetic resonance imaging in the pivotal Joint Outcomes Study suggest that prophylaxis prevents chronic microhemorrhage into the joints, as well as clinically obvious hemarthrosis. ${ }^{4}$ Furthermore, prophylaxis is associated with fewer work and school absences, ${ }^{12}$ improved physical health-status scores, decreased pain, and higher health-related quality-of-life $(\mathrm{QoL})$ scores (measured using either generic or hemophilia-specific questionnaires). ${ }^{10,13-15}$ New evidence suggests that starting prophylaxis as early as possible, prior to joint bleeding, ensures the best efficacy. ${ }^{16}$

Prophylaxis may be initiated before or after onset of joint bleeding and joint disease. Primary prophylaxis has been defined as regular, continuous replacement therapy started in the absence of joint disease and before the second joint bleed and age 3 years; secondary prophylaxis as regular, continuous replacement therapy started before the onset of joint disease and after two or more joint bleeds; and tertiary prophylaxis 
as regular, continuous replacement therapy started after the onset of joint disease. ${ }^{17}$ The continuous prophylaxis definition includes a requirement that the individual receive "a minimum of an a priori defined frequency of infusions for at least 45 weeks (85\%) of the year". ${ }^{17}$

In light of the demonstrated benefits of prophylaxis in hemophilia, the Medical and Scientific Advisory Council of the National Hemophilia Foundation recommends that prophylaxis begin at a young age, ${ }^{18}$ prior to the onset of recurrent bleeding, in children with severe hemophilia A and B. ${ }^{18}$ These guidelines suggest that prophylaxis should be given to target a trough FVIII or FIX level $>1 \%$. Notably, current guidelines do not provide a recommendation for prophylaxis in those with mild-moderate hemophilia; however, even infrequent bleeding events (eg, once or twice yearly) can lead to arthropathy, ${ }^{19}$ and there is evidence to support the effectiveness of prophylaxis in this population. ${ }^{20}$ There is no published guidance regarding the age at which to stop prophylaxis, although continued prophylaxis on an individualized basis may benefit adults with hemophilia. ${ }^{18,21-23}$

Given the improved outcomes associated with prophylaxis and the importance of adherence to these regimens in achieving these outcomes, this article reviews the current rates of adherence to prophylaxis regimens (with a focus on US-based studies), discusses barriers to adherence, describes the impact of treatment adherence on clinical and economic outcomes, and identifies approaches to improve health outcomes.

\section{Rates of prophylaxis prescription and usage}

Despite the current recommendations and evidence base, prescription of prophylaxis for people with severe hemophilia is not universal. ${ }^{24}$ Table 1 summarizes reported data on prophylaxis rates over time. Primary sources include the Centers for Disease Control and Prevention (CDC) Universal Data Collection (UDC) program, the American Thrombosis and Hemostasis data set, and physician surveys. ${ }^{25-29}$ Overall, prescription of prophylaxis has increased over time. Rates are highest in patients with severe hemophilia A and in the age range of 2-15 years.

Notably, in a 2003 global survey of hemophilia-treatment centers (HTCs; the International Hemophilia A Practice Patterns Survey), rates of hemophilia A prophylaxis prescription (sum of primary, secondary continuous, and secondary intermittent) in the US were lower than those reported for the UK, Canada, Australia, and Sweden. However, US rates were higher than those in a combined measure of other countries (including Belgium, Brazil, Finland, Hungary, Iceland, Israel, Japan, Malaysia, Mexico, the Netherlands, New Zealand, South Africa, Spain, and Taiwan). ${ }^{30}$ In a follow-up Practice Patterns Survey in 2005 using the same questionnaire, the percentage of HTCs prescribing primary prophylaxis for severe hemophilia A had significantly increased in the US, from $19 \%$ in 2003 to $28 \%$ in $2005(P<0.0001)$, with a corresponding decrease in on-demand treatment. ${ }^{31}$ The proportion of clinicians prescribing secondary prophylaxis remained stable. A similar pattern was observed in the UK, with significantly increased use of primary prophylaxis for severe hemophilia A from 2003 $(30 \%)$ to $2005(38 \%)$ and generally stable rates of secondary prophylaxis during this time. ${ }^{31}$ In both surveys, prophylaxis prescription was almost $100 \%$ in Swedish HTCs. ${ }^{30,31}$

\section{Treatment-adherence rates in hemophilia}

A number of studies have measured adherence to prophylaxis in children and adults with hemophilia. Adherence is defined as the active, voluntary, and collaborative involvement of a

Table I Adherence rates with continuous prophylaxis for patients with hemophilia over time

\begin{tabular}{|c|c|c|c|c|c|c|}
\hline \multirow[t]{2}{*}{ Data source } & \multirow[t]{2}{*}{ Type of study } & \multirow[t]{2}{*}{ Time frame } & \multicolumn{4}{|c|}{ Rate of prophylaxis by disease severity (\%) } \\
\hline & & & Severe & Moderate & Mild & Unknown \\
\hline \multirow[t]{3}{*}{ CDC UDC program ${ }^{25}$} & Observational prospective & $1998-2004$ & A: 35.3 & A: 13.4 & A: 0.6 & NA \\
\hline & & & B: 27.1 & B: 6 & B: 0.7 & \\
\hline & & & $A+B: 34$ & $A+B: I I$ & $A+B: 0.7$ & \\
\hline CDC UDC program ${ }^{26}$ & Observational prospective & $2005-2009$ & $A+B: 48$ & $A+B: 16.2$ & $A+B: 2.1$ & $A+B: 27.8$ \\
\hline \multirow[t]{3}{*}{ Blanchette et $\mathrm{a}^{27}$} & Survey of North American & 2002 & A: 47 & A: 13 & A: 0 & NA \\
\hline & HTC clinicians* & & B: 30 & B: 3 & B: 0 & \\
\hline & & & $A+B: 44.2$ & $A+B: 12.9$ & $A=B$ & \\
\hline \multirow[t]{3}{*}{ Zappa et $\mathrm{a}^{28}$} & Survey of North American & 2010 & A: 58 & NA & NA & NA \\
\hline & HTC clinicians & & B: 5 I & & & \\
\hline & & & $A+B: 56.8$ & & & \\
\hline \multirow[t]{2}{*}{ ATHN data $\operatorname{set}^{29}$} & Registry & $2010-2015$ & A: 67.6 & A: 30.1 & A: 4.4 & A: 7.5 \\
\hline & & & B: 60.7 & B: $14 . \mid$ & B: 4.5 & B: 6.2 \\
\hline
\end{tabular}

Note: *Patients aged $\leq 18$ years only.

Abbreviations: CDC, Centers for Disease Control and Prevention; UDC, Universal Data Collection; NA, not applicable; HTC, hemophilia-treatment center; ATHN, American Thrombosis and Hemostasis Network; A, FVIII deficiency; B, FIX deficiency. 
patient in a mutually acceptable course of behavior to produce a desired preventive or therapeutic result. ${ }^{32}$ In clinical research, adherence is generally quantified by the number of doses of medication administered compared with the number of doses prescribed. Definitions of acceptable adherence differ substantially across studies. In general, across disease states, excellent adherence is commonly but arbitrarily defined as administering at least $75 \%-80 \%$ of doses/medication..$^{24,33-36}$ Measures of treatment adherence also vary widely in clinical practice and clinical study reporting,,$^{34,37,38}$ and may include data from the review of treatment logs, pharmacy records, bleed frequency (including joint bleeds), school attendance, and participation in physical activity/sports. ${ }^{24,39}$ All these methods are subject to inherent bias and confounding factors, and a combination of methods is required to assess adherence accurately. Also, few measures capture all the elements of adherence. For example, a patient may infuse the correct dose on the recommended days of the week, but infuse in the evening rather than the recommended morning. This patient could be considered partially adherent.

In hemophilia-adherence research, a measure called the VERITAS-Pro (Validated hEmophilia-RegImen TreatmentAdherence Scale-Prophylaxis) was developed and validated to provide a standardized method for evaluating adherence to prophylaxis. The VERITAS-Pro consists of 24 questions utilizing 5-point Likert scales, with total scores ranging from 24 (most adherent) to 120 (least adherent). In addition to producing a total adherence score, questions are divided into six subscales (time, dose, plan, remember, skip, and communicate) to delineate the areas of nonadherence, such that this scale addresses the details about the quality of adherence. The primary infuser (patient or caregiver) completes the scale. The VERITAS-Pro has been translated into more than 30 languages. It provides clinicians the opportunity to tailor interventions to improve patient adherence using individualized patient-reported information about specific issues underlying nonadherence. ${ }^{40}$

\section{Patient-reported adherence}

Patient-reported adherence rates from patient surveys, pharmacy logs, and infusion logs are shown in Table 2. Overall, reported adherence is highest in young children. For example, a US-based study evaluated adherence to prophylaxis using the VERITAS-Pro and found that pediatric patients $(n=47)$ reported significantly better adherence compared with adults $(n=23)$, with scores of 38 and 45.8 , respectively $(P<0.05) .{ }^{41}$ In accordance with this result, a second study, including adults with moderate or severe hemophilia and caregivers of children with moderate or severe hemophilia, was conducted in the US, Canada, and Australia (110 total respondents) ${ }^{43}$ Mean VERITAS-Pro scores of 39.6 and 50.8 were reported by caregivers of children with hemophilia and by adults with hemophilia, respectively $(P<0.001){ }^{43}$

\section{Health-care provider adherence assessments}

Two studies evaluated health-care provider-reported rates of adherence to prophylaxis. Surveys published in 2008 and 2012 conducted with HTC clinicians employed similar questionnaires and defined adherence as administration of $\geq 80 \%$ of the prescribed number of infusions to children with hemophilia. In the 2008 survey $(n=59), 54 \%$ of clinicians perceived that $>75 \%$ of patients met the adherence criteria; in the 2012 survey ( $\mathrm{n}=48)$, this number had fallen to $42 \%$ of clinicians. ${ }^{24,35}$

A 2010 survey of US HTC nurses conducted as part of the Practice Patterns Survey identified varying definitions of adherence used in clinical practice: no breakthrough bleeds (except for trauma situations), no deterioration in joint health, and patients following the physician's prophylaxis prescription. ${ }^{28}$ Adherence was defined as reported prophylactic doses per month divided by prescribed prophylactic doses per month. Eighty percent and 78\% for severe hemophilia $\mathrm{A}$ and $\mathrm{B}$, respectively, achieved this criterion. Estimated

Table 2 Patient-reported rates of adherence with prophylaxis

\begin{tabular}{|c|c|c|c|c|}
\hline Reference & Data source & Age & Definition of adherence & Reported adherence \\
\hline 31 & Survey & $1-18$ years & $>75 \%$ of prescribed infusions & $58.8 \%$ adherent \\
\hline 32 & Survey & Children and adults & $>80 \%$ of prescribed infusions & $73 \%$ adherent \\
\hline 41 & VERITAS-Pro & Adolescents & Score of $\geq 57$ & $30 \%$ adherent \\
\hline 42 & Pharmacy logs & Children and adults & Days supply/days observed $\geq 60 \%$ & Adherence achieved $50 \%$ of the time \\
\hline 36 & Infusion logs & Children and adults & $>67 \%$ weeks of prophylaxis & $\begin{array}{l}\text { Children: } 26 \\
\text { Adults: } 39\end{array}$ \\
\hline 37 & Infusion logs & Adults, 18-56 years & $\begin{array}{l}\text { Study scoring system to rate } \\
\text { adherence with frequency and dosage }\end{array}$ & $\begin{array}{l}\text { Median adherence to frequency: } 76 \% \\
\text { Median adherence to dosage: } 93 \%\end{array}$ \\
\hline 4 & $\begin{array}{l}\text { Randomized controlled } \\
\text { trial, infusion logs }\end{array}$ & 6 months -6 years & Not defined & $\begin{array}{l}\text { Mean adherence } 96 \% ; 2 \text { of } 32 \text { had } \\
\text { difficulty with infusion schedule }\end{array}$ \\
\hline
\end{tabular}


adherence was highest among those aged $\leq 2$ years $(90 \%)$ and lowest among those aged $18-24$ years $(64 \%) .{ }^{28}$

Physician-prescribing patterns and perceptions of adherence to prophylaxis are likely interrelated. In a physician survey, 34\% reported that in the last year, they had not prescribed prophylaxis for some people with hemophilia (PWH), due to concerns about nonadherence. ${ }^{35}$ Walsh and Valentino also reported that nonadherence was a reason for modifying the treatment regimen in $32 \%$ of subjects. ${ }^{44}$

\section{Barriers to treatment adherence}

Barriers to adherence to prophylaxis have been reported by patients, caregivers, and health-care providers (Table 3 ). There are five key types of adherence barriers: patient-related factors, condition-related factors, treatment-related factors, health-care system factors, and socioeconomic factors.

\section{Patient-related factors}

Patient health beliefs relate strongly to adherence. Health beliefs influence the acceptance of the diagnosis and understanding of disease consequences and the benefits of a given therapy. The effect of health beliefs on the likelihood of adherence is described by the health-belief model. ${ }^{47}$ An individual's perception of susceptibility to illness, severity of the consequences of illness, and belief in the potential of treatment to reduce the consequences may play a role in adherence. ${ }^{48}$ For example, the likelihood that patients with

Table 3 Barriers to prophylaxis adherence and potential strategies for addressing these barriers

\begin{tabular}{ll}
\hline Barriers to adherence ${ }^{28,31,42,45-49}$ & $\begin{array}{l}\text { Potential strategies to } \\
\text { improve adherence }{ }^{50-56}\end{array}$ \\
\hline - Patient-related factors & Education (multimedia, peer- \\
$\circ$ Health beliefs & to-peer mentors, tailored to \\
$\circ$ Age & patient's primary language, \\
- Condition-related factors & development, and health literacy) \\
$\circ$ Frequency of bleeding & $\circ$ Benefits of prophylaxis \\
- Treatment-related factors & $\circ$ Venous access \\
$\circ$ Venous access & $\circ$ Health-care navigation \\
$\circ$ Dosing regimen & $\circ$ Patient portals in ehealth \\
$\circ$ Cost & records \\
$\circ$ Perceived costs & Monitoring \\
- Health-care system factors & $\circ$ Logs \\
$\circ$ Access to hemophilia- & $\circ$ Mobile direct observation \\
treatment center & Reminders \\
$\circ$ Insurance & $\circ$ Text messaging \\
\hline Socioeconomic factors & $\circ$ Phone app \\
$\circ$ Language & Incentives (age-appropriate) \\
$\circ$ Acculturation & $\circ$ Reward charts \\
$\circ$ Health literacy & $\circ$ Financial \\
$\circ$ Balancing the child's care with & \\
\hline other family and social needs & \\
\hline
\end{tabular}

severe hemophilia A will administer prophylactic infusions depends on the perceptions that they are susceptible to joint bleeds, which will lead to chronic arthropathy, and that infusions will prevent these complications. The impact of these basic perceptions on treatment adherence is modified by many other factors, including such barriers as time constraints, venous access, and cost.

Schrijvers et al found that adherence depends on patient acceptance of hemophilia, feeling or fearing the symptoms of hemophilia, and having planning skills to implement prophylaxis. ${ }^{57}$ The authors suggested that adherence varied in different subgroups, ranging from best to worst adherence: 1) prophylaxis is integrated into life, 2) prophylaxis is according to physician advice, struggling with irregular situations, 3) prophylaxis is too much to handle, and 4) prophylaxis is a confrontation with illness.

Other patient-related factors are previous illness experience, previous adherence history, comorbidities, cognitive impairment, and mental illness, including depression. ${ }^{49}$ Age is also an important modifying factor. Young children and the elderly depend on others for appropriate medical care, whereas adolescents, young adults, and middle-aged adults are typically independent. Social concerns play a large role, especially among adolescents who want to fit in with their peers and be unbothered by illness.

Young adult PWH (YA-PWH) are at high risk of discontinuing prophylaxis and poor adherence. This is at least partially attributable to the numerous changes that occur during this time, including transferring care from pediatric to adult health-care systems and assuming responsibility for medical care. ${ }^{42,58}$

Quon et al summarized these key unmet challenges for young adults with hemophilia:

The need to proactively establish responsibility for health care decisions with diminishing family influence; unfamiliarity with adult HTC providers and policies, coupled with the loss of access to pediatric health care providers with whom YA-PWH have developed long-standing relationships; and an unconvincing value proposition of regular adult HTC visits in the age of prophylaxis. ${ }^{59}$

These barriers and challenges are concerning, since bleeding rates increase in adolescents and young adults who discontinue prophylaxis. ${ }^{44}$

\section{Condition-related factors}

Condition-related factors include duration and severity of illness. For example, medication adherence may be high 
initially but wane over time, particularly if the patient becomes asymptomatic. An international survey of patients and nurses identified infrequent bleeds as the greatest barrier to adherence. ${ }^{30}$ Patients experiencing few bleeds or who do not recognize bleeds may perceive lower susceptibility to illness or underestimate the severity of consequences of illness. ${ }^{42,60}$ This is especially true for patients who started prophylaxis at a young age and may not have experienced bleeding events or their consequences. ${ }^{50}$ Children who are on prophylaxis must be taught what a bleed feels like, so they can recognize and treat breakthrough bleeding as soon as possible. Patients and caregivers should also be educated that prophylaxis likely prevents microbleeds and is thus critical, even when patients are asymptomatic. ${ }^{4}$

\section{Treatment-related factors}

Complex regimens based on dosage frequency, dosage amount, form of drug, and delivery method can interfere with adherence. In a survey of US children and adults receiving prophylaxis for hemophilia A or B, those who reported excellent or less-than-excellent adherence identified the time-consuming nature of their prophylaxis regimen as the most important adherence barrier. ${ }^{33}$ Prophylaxis regimens typically involve two to four infusions per week, each taking $2->50$ minutes, depending on the clotting-factor formulation and preparation required. ${ }^{18,61}$ It is difficult for many parents of children with hemophilia to fit such a time-intensive regimen into their morning routines and still arrive at school and work on time. ${ }^{61}$

Perceived harm and risks may interfere with adherence. Parents commonly cite difficulty with venous access or "sticking" the child as an adherence-related challenge. ${ }^{31}$ Venous access issues are often most distressing for the youngest patients: one Japanese study reported this as the most important barrier to adherence in children aged $<5$ years. ${ }^{62}$ In a 2006 international survey, other important concerns of nurses, patients, and caregivers included the risk of infection and thrombosis associated with venous administration, and an inability to maintain the intravenous line; $39 \%$ of nurses identified the potential risks associated with plasma-derived products as a barrier to prophylaxis. Since utilization of plasma-derived products is relatively low in the US, this barrier is not significant there. ${ }^{30}$

Cost of treatment is frequently cited as a critical challenge to prophylaxis adherence in hemophilia. Although prophylaxis is cost-effective in comparison with episodic treatment, the overall cost is high. ${ }^{63,64}$ In the 2006 survey just cited, $45 \%$ of nurses from all countries identified cost concerns as a significant barrier to prophylaxis, a particular issue for US-based nurses. ${ }^{31}$ Reported estimates of the cost of prophylaxis vary according to factors including study date, disease severity, and inhibitor status. Few estimates based on US care and insurance systems have been published. In the landmark 2007 US study by Manco-Johnson et $\mathrm{al},{ }^{4}$ it was estimated that for a $50 \mathrm{~kg}$ child with severe hemophilia A, the annual cost of prophylaxis could reach $\$ 300,000$ (2007 prices). In a 1995 US study, the estimated annual cost of prophylaxis in an adult with severe hemophilia A and no arthropathy or inhibitors was $\$ 69,656 .{ }^{65}$ A 2010 European study estimated the average lifetime cost of severe hemophilia A at $€ 166,168,643 .{ }^{63}$ In all these studies, the vast majority of the cost was accounted for by clotting-factor consumption. Because clotting-factor dose is based on body weight, the cost of the clotting factor will be increased in overweight or obese individuals. ${ }^{66}$ It is estimated that $~ 30 \%$ of patients with hemophilia in the US are uninsured or underinsured (although this figure may change with the evolving US health-care landscape). Out-of-pocket costs for insured and uninsured patients may cause them to forgo medication doses or prophylaxis entirely. ${ }^{67}$ The economic downturn of recent years also had an impact on adherence to prophylaxis, with patients skipping/reducing clotting factor doses or skipping prescription refills. ${ }^{68}$

\section{Health-care system factors}

Health-care system factors include access to care (distance to HTC) and access to factor (insurance, need for prior authorization). As adolescents transition to adult care, they may experience difficulty navigating the health-care system and maintaining health insurance, and in turn have decreased adherence to prophylaxis. Adolescents who move away to college are at high risk of poor outcomes. In college, adolescents and young adults need to assume many new roles, such as performing self-infusions (if not started at a younger age), managing clotting-factor refills and storage, remembering the prophylaxis schedule, keeping track of appointments, and understanding medical insurance. Relationships with the HTC team may impact adherence as well. Tran et al showed that trust in the physician was associated with improved adherence. $^{49}$

\section{Socioeconomic factors}

Socioeconomic factors include family size, family structure, social support, income/insurance, health literacy, language, and culture. These factors affect the family's ability to understand the disease and disease consequences and how to take 
the medication. Family or cultural norms may affect patient willingness to accept treatment recommendations.

\section{Impact of treatment adherence on outcomes}

The established benefits of prophylaxis compared to episodic treatment with regard to decreases in bleeding events (including joint bleeds) and joint damage, and improved $\mathrm{QoL}^{4-13}$ are dependent on adherence to prescribed regimens. ${ }^{38,69,70}$

A recent study assessed the relationship between adherence to prophylaxis, as measured by the VERITAS-Pro, and annual bleeding rate (ABR). ${ }^{71}$ In the poor-adherence group, a higher proportion of subjects experienced one or more bleeds annually than those in the good-adherence group (86\% vs $62 \%$ ). A separate 2014 survey of 55 adults with hemophilia and 55 caregivers of children with hemophilia also correlated poor adherence (again measured using the VERITAS-Pro) with increased self-reported breakthrough bleeding and target joint bleeds in the preceding year. ${ }^{43}$ A cohort study of 44 patients with severe hemophilia A demonstrated that increasing time with $<1 \%$ FVIII-activity level was associated with increased bleeding events and hemarthrosis. ${ }^{69}$ Time spent at $<1 \%$ was affected by adherence; patients with low adherence rates experienced more bleeds. Therefore, adherence to a prophylactic regimen may reduce the frequency of bleeding events. Another cohort study of 49 patients with severe hemophilia demonstrated that patients receiving prophylaxis who discontinued treatment of their own accord for varying periods generally had a greater number of joint bleeds and higher scores on the Pettersson scale, indicating more severe arthropathy. ${ }^{70}$

Other studies have demonstrated a relationship between adherence to prophylaxis and pain. In US adults and children with hemophilia using high-intensity treatment regimens (including prophylaxis), greater adherence was associated with better bodily pain scores on a QoL measure compared with lower adherence. ${ }^{38} \mathrm{~A}$ more recent US study confirmed an inverse relationship between treatment adherence and chronic pain in adolescents and young adults with moderate or severe hemophilia. ${ }^{72}$

Adherence to prophylaxis may also affect economic outcomes, including direct treatment costs and indirect costs, such as those due to work/school absenteeism. A 2014 survey found that poor adherence was associated with more missed school days among children with hemophilia. ${ }^{43}$ Overall, studies have suggested that prophylaxis is cost-effective. ${ }^{63}$ Finally, Iorio et al developed a model to predict ABR, comparing prophylaxis with standard half-life products to extended half-life products at different adherence levels. ABR was lower with extended-half life products at each adherence level. $^{73}$

\section{Expert opinion Strategies to address adherence to prophylaxis}

Strategies are needed to align prophylaxis recommendations with patients' goals and skills. Types of interventions may include educational, cognitive/behavioral, and skill training (Table 3). These approaches need to account for individual patient factors, such as age, developmental stage, prior hemophilia history, comorbidities, mental illness, and socioeconomic status. For example, strategies to increase adherence in the youngest patients must target caregivers responsible for treatment administration, whereas strategies for adolescents and adults will target patients directly. It is especially important to create strategies targeting adolescents, as they become increasingly independent and take on responsibility for self-care, including factor infusions. ${ }^{74-76}$ The National Hemophilia Foundation Steps for Living program has excellent resources for 18 - to 25 -year-olds.

Providers need to work closely with patients to understand their needs and promote adherence. The British Columbia Hemophilia Adult Team recommends that providers deemphasize adherence as a primary goal and instead focus on the patient, developing customized treatment based on his/her priorities. Allowing the patient to design the treatment plan with the medical team may improve adherence..$^{51}$ Patient navigators can also help patients adhere to a prophylaxis regimen by helping them attend appointments, maintain insurance, and obtain clotting-factor refills. Patient navigators have a critical role when patients transfer between health-care teams.

Because belief in treatment necessity is a motivator for treatment adherence, repeated education is an important strategy for improving adherence in hemophilia. Indeed, health literacy has been positively associated with adherence, and health-literacy interventions increase both health-literacy and adherence outcomes. ${ }^{77}$ Education can occur via written/ verbal communication during clinic visits and potentially through such programs as peer-to-peer mentoring. Education should be tailored to the patient's primary language, development, and current health literacy, avoiding jargon and complex details. Educational content should include the reason for the medication, expected duration, expected response, side effects, monitoring, how to obtain medication, and how to take the medication. 
In addition to interventions to improve health literacy, other socioeconomic barriers to adherence to prophylaxis in hemophilia may be best addressed by the HTC social workers or other psychosocial support personnel. Identifying the sources of family financial support, obtaining family support in administering a medication, offering emotional support, encouraging family cohesion, helping the patient's mother to develop a realistic perception of disease severity, supervising medication administration, and assisting patients to find health insurance have been identified as socioeconomic variables having a positive effect on adherence. ${ }^{78}$ For YA-PWH, additional strategies may include educating HTC staff about the challenges of transition and transfer of care: improving education among adolescents such that YA-PWHs are prepared for the challenges of young adulthood, educating YA-PWH about the utility of regular comprehensive care, and increasing access to care for patients who live remotely or work or attend college during the day. ${ }^{59}$

Motivational techniques may be implemented to improve self-care..$^{52}$ Providers can teach parents communication strategies to motivate children to take part in their health care and decision-making, going beyond simple illness management to a broader scope that allows autonomy and encourages children to take responsibility for their own health and risk behaviors.

Behavioral strategies to increase the feasibility of peripheral infusions can make administering clotting factor less daunting. Support and education can help young patients become self-sufficient in this technique, which may give them a sense of achievement and confidence in dealing with problems. ${ }^{71}$ Hemophilia summer camp is an important venue for formal education, as well as peer-to-peer education and motivation regarding home therapy and development of the independence and confidence necessary for self-infusion. ${ }^{61,79}$

Electronic media are also useful in the delivery of educational content regarding hemophilia care and adherence. In a study of adolescents with hemophilia, an interactive website was developed specifically for teenagers with hemophilia to assist in transition from pediatric to adult care ${ }^{54}$ Content included hemophilia-specific education, self-management strategies, images, interactive animations, videos with health-care professionals, quizzes, and a glossary. User feedback was positive, with a significant change from baseline in self-efficacy and transition preparedness; the specific effect on adherence was not reported. ${ }^{55}$

Additionally, mobile-device apps on smartphones can send prophylaxis reminders to patients and provide encouragement. ${ }^{56}$ Electronic logs aid health-care providers in real-time recognition of nonadherence and in targeting strategies for improving adherence. Patients and providers can also use resources within electronic health records, eg, patient portals, to communicate about prophylaxis.

New technologies in the treatment of other chronic and long-term conditions may be applied to PWH. Direct mobile observation of treatment in patients with tuberculosis has been accomplished by having treatment supporters record mobile-phone videos of patients taking their medication. ${ }^{80}$ The videos were reviewed by health-care professionals, who then responded with motivational and educational text messages to the patients. The majority of study participants preferred this to in-person visits with health-care professionals. Such an approach could be adopted for hemophilia patients administering home infusions, allowing them to ask their clinician questions during the interaction.

The use of financial incentives has been shown to enhance adherence in subjects requiring warfarin therapy. Daily reminders were sent from an electronic monitoring system, and adherence was measured with the international normalized ratio (INR) for warfarin. The incentive to take warfarin correctly was entry into a daily lottery with the chance of winning cash prizes. During the study, the number of pills taken incorrectly decreased significantly and the time out of INR range significantly reduced. ${ }^{81}$ Such an approach might be considered in patients with hemophilia.

\section{Potential impact of new therapies on adherence}

Patients typically infuse standard FVIII products three to four times per week for prophylaxis..$^{18} \mathrm{New}$ extended half-life FVIII products are infused approximately one to two times per week. ${ }^{82,83}$ Similarly, patients typically infuse standard FIX products two to three times per week for prophylaxis. ${ }^{18}$ New extended half-life FIX products are infused once every 1-2 weeks. Intravenous administration is a key barrier to prophylaxis; the development of factor and non-factorreplacement products given subcutaneously may increase prescription of and adherence to prophylaxis.

Development of new clotting-factor products that reduce dosing frequency has the potential to enhance adherence and patient acceptance of prophylaxis by reducing the infusionschedule burden. However, as with all treatment regimens, the patient's new infusion schedule should be simple to implement and acceptable to the patient. While many patients adapt well to new infusion schedules, some patients may have difficulty transitioning from infusing Monday, Wednesday, 
and Friday, eg, to every fourth or fifth day. In these situations, new strategies to promote adherence and provide dosing reminders (eg, mobile-phone apps) may be helpful.

Prophylaxis regimens that allow for less frequent infusions may mitigate difficulties with venous access and time constraints. It may be possible for young children to receive prophylaxis via peripheral infusion, and ports may be discontinued at a younger age when infusions are less frequent. Alternatively, patients may agree to prophylaxis if they perceive that they will have "better protection" with the new products. Increased physical activity and improved QoL are the important patient outcomes that have been shown with new, extended half-life factors. ${ }^{84-86}$ The availability of new factor products also provides clinicians new opportunities to educate patients and families about the benefits of prophylaxis.

\section{Summary}

In summary, prophylaxis is proven to improve health outcomes in patients with hemophilia. There are several barriers to adherence to prophylaxis. Therefore, clinicians should identify and mitigate potential barriers at the onset of therapy, and continuously monitor for decreased adherence. Strategies to improve adherence should be used with patients who are at risk for or have poor adherence. Extended half-life factor products and subcutaneous administration of prophylaxis have the potential to decrease the burden of prophylaxis and improve adherence, ultimately resulting in improved health outcomes.

\section{Acknowledgments}

Bioverativ and Sobi reviewed and provided feedback on the paper. The authors had full editorial control of the paper and provided their final approval of all content.

\section{Author contributions}

All authors contributed to the development of this review article, revised the paper critically, and approved the submitted and final versions.

\section{Disclosure}

CDT serves on the Data Safety Monitoring Board for Biogen; has been an advisory-board participant for Octapharma, Shire, and CSL Behring; and has received research funding from Shire and Bayer Pharmaceuticals. NAD reports no conflicts of interest in this work.

\section{References}

1. Bolton-Maggs PH, Pasi KJ. Haemophilias A and B. Lancet. 2003; 361(9371):1801-1809.
2. Mannucci PM, Tuddenham EG. The hemophilias: from royal genes to gene therapy. N Engl J Med. 2001;344(23):1773-1779.

3. Berntorp E, Shapiro AD. Modern haemophilia care. Lancet. 2012; 379(9824):1447-1456.

4. Manco-Johnson MJ, Abshire TC, Shapiro AD, et al. Prophylaxis versus episodic treatment to prevent joint disease in boys with severe hemophilia. N Engl J Med. 2007;357(6):535-544.

5. Iorio A, Marchesini E, Marcucci M, Stobart K, Chan AK. Clotting factor concentrates given to prevent bleeding and bleeding-related complications in people with hemophilia A or B. Cochrane Database Syst Rev. 2011;(9):CD003429.

6. Panicker J, Warrier I, Thomas R, Lusher JM. The overall effectiveness of prophylaxis in severe haemophilia. Haemophilia. 2003;9(3): 272-278.

7. Fischer K, van der Bom JG, Molho P, et al. Prophylactic versus ondemand treatment strategies for severe haemophilia: a comparison of costs and long-term outcome. Haemophilia. 2002;8(6):745-752.

8. Gringeri A, Lundin B, von Mackensen S, Mantovani L, Mannucci PM. A randomized clinical trial of prophylaxis in children with hemophilia A (the ESPRIT study). J Thromb Haemost. 2011;9(4):700-710.

9. Ingerslev J, Lethagen S, Poulsen LH, et al. Long-standing prophylactic therapy vs. episodic treatment in young people with severe haemophilia: a comparison of age-matched Danish and Russian patients. Haemophilia. 2014;20(1):58-64.

10. Löfqvist T, Nilsson IM, Berntorp E, Pettersson H. Haemophilia prophylaxis in young patients: a long-term follow-up. J Intern Med. 1997;241(5):395-400.

11. Nilsson IM, Berntorp E, Löfqvist T, Pettersson H. Twenty-five years' experience of prophylactic treatment in severe haemophilia A and B. J Intern Med. 1992;232(1):25-32.

12. Krishnan S, Furlan JV, Duncan N. Adherence to prophylaxis is associated with better outcomes in moderate and severe haemophilia: results of a patient survey. Haemophilia. 2015;21:64-70.

13. Royal S, Schramm W, Berntorp E, et al. Quality-of-life differences between prophylactic and on-demand factor replacement therapy in European haemophilia patients. Haemophilia. 2002;8(1):44-50.

14. Garcia-Dasi M, Aznar JA, Jimenez-Yuste V, et al. Adherence to prophylaxis and quality of life in children and adolescents with severe haemophilia A. Haemophilia. 2015;21(4):458-464.

15. McLaughlin JM, Witkop ML, Lambing A, Anderson TL, Munn J, Tortella B. Better adherence to prescribed treatment regimen is related to less chronic pain among adolescents and young adults with moderate or severe haemophilia. Haemophilia. 2014;20(4):506-512.

16. Nijdam A, Foppen W, van der Schouw YT, Mauser-Bunchschoten EP, Schutgens RE, Fischer K. Long-term effects of joint bleeding before starting prophylaxis in severe haemophilia. Haemophilia. 2016;22(6): 852-858.

17. Blanchette VS, Key NS, Ljung LR, Manco-Johnson MJ, van den Berg HM, Srivastava A. Definitions in hemophilia: communication from the SSC of the ISTH. J Thromb Haemost. 2014;12(11):1935-1939.

18. National Hemophilia Foundation. MASAC recommendation concerning prophylaxis (regular administration of clotting factor concentrate to prevent bleeding). 2016. Available from: http://www.hemophilia. org/sites/default/files/document/files/241Prophylaxis.pdf. Accessed March 27, 2017.

19. den Uijl I, Fischer K, van der Bom JG, Grobbee DE, Rosendaal FR, Plug I. Clinical outcome of moderate haemophilia compared with severe and mild haemophilia. Haemophilia. 2009;15(1):83-90.

20. den Uij1 I, Biesma D, Grobbee D, Fischer K. Outcome in moderate haemophilia. Blood Transfus. 2014;12(Suppl 1):S330-S336.

21. Srivastava A, Brewer AK, Mauser-Bunschoten EP, et al. Guidelines for the management of hemophilia. Haemophilia. 2013;19(1):e1-e47.

22. Hay CR. Prophylaxis in adults with haemophilia. Haemophilia. 2007; 13(Suppl 2):10-15.

23. van Dijk K, Fischer K, van der Bom JG, Scheibel E, Ingerslev J, van den Berg HM. Can long-term prophylaxis for severe haemophilia be stopped in adulthood? Results from Denmark and the Netherlands. Br J Haematol. 2005;130(1):107-112. 
24. Thornburg CD. Physicians' perceptions of adherence to prophylactic clotting factor infusions. Haemophilia. 2008;14(1):25-29.

25. Centers for Disease Control and Prevention. Report on the Universal Data Collection Program. Atlanta: CDC; 2005.

26. Centers for Disease Control Prevention. Report on the Universal Data Collection Program. Atlanta: CDC; 2014.

27. Blanchette VS, McCready M, Achonu C, Abdolell M, Rivard G, Manco-Johnson MJ. A survey of factor prophylaxis in boys with haemophilia followed in North American haemophilia treatment centres. Haemophilia. 2003;9(Suppl 1):19-26.

28. Zappa S, McDaniel M, Marandola J, Allen G. Treatment trends for haemophilia A and haemophilia B in the United States: results from the 2010 practice patterns survey. Haemophilia. 2012;18(3):e140-e153.

29. American Thrombosis and Hemostasis Network. ATHN Research Report Brief: ATHN Dataset - December 31, 2014. Chicago: ATHN; 2015.

30. Geraghty S, Dunkley T, Harrington C, Lindvall K, Maahs J, Sek J. Practice patterns in haemophilia A therapy: global progress towards optimal care. Haemophilia. 2006;12(1):75-81.

31. Khair K, Lawrence K, Butler R, O'Shea E, Christie BA. Assessment of treatment practice patterns for severe hemophilia A: a global nurse perspective. Acta Haematol. 2008;119(2):115-123.

32. Meichenbaum D, Turk DC. Facilitating Treatment Adherence. New York: Plenum Press; 1987.

33. Hacker MR, Geraghty S, Manco-Johnson M. Barriers to compliance with prophylaxis therapy in haemophilia. Haemophilia. 2001;7(4): 392-396.

34. Thornburg CD, Pipe SW. Adherence to prophylactic infusions of factor VIII or factor IX for haemophilia. Haemophilia. 2006;12(2): 198-199.

35. Thornburg CD, Carpenter S, Zappa S, Munn J, Leissinger C. Current prescription of prophylactic factor infusions and perceived adherence for children and adolescents with haemophilia: a survey of haemophilia healthcare professionals in the United States. Haemophilia. 2012;18(4):568-574.

36. Osterberg L, Blaschke T. Adherence to medication. NEngl J Med. 2005; 353(5):487-497.

37. Tencer T, Roberson C, Duncan N, Johnson K, Shapiro A. A haemophilia treatment centre-administered disease management programme in patients with bleeding disorders. Haemophilia. 2007;13(5):480-488.

38. du Treil S, Rice J, Leissinger CA. Quantifying adherence to treatment and its relationship to quality of life in a well-characterized haemophilia population. Haemophilia. 2007;13(5):493-501.

39. Ho S, Gue D, McIntosh K, Bucevska M, Yang M, Jackson S. An objective method for assessing adherence to prophylaxis in adults with severe haemophilia. Haemophilia. 2014;20(1):39-43.

40. Duncan N, Kronenberger W, Roberson C, Shapiro A. VERITAS-Pro: a new measure of adherence to prophylactic regimens in haemophilia. Haemophilia. 2010;16(2):247-255.

41. Duncan N, Shapiro A, Ye X, Epstein J, Luo MP. Treatment patterns, healthrelated quality of life and adherence to prophylaxis among haemophilia A patients in the United States. Haemophilia. 2012;18(5):760-765.

42. Witkop ML, McLaughlin JM, Anderson TL, Munn JE, Lambing A, Tortella B. Predictors of non-adherence to prescribed prophylactic clotting-factor treatment regimens among adolescent and young adults with a bleeding disorder. Haemophilia. 2016;22(4):e245-e250.

43. Krishnan S, Vietri J, Furlan R, Duncan N. Adherence to prophylaxis is associated with better outcomes in moderate and severe haemophilia: results of a patient survey. Haemophilia. 2015;21(1):64-70.

44. Walsh CE, Valentino LA. Factor VIII prophylaxis for adult patients with severe haemophilia A: results of a US survey of attitudes and practices. Haemophilia. 2009;15(5):1014-1021.

45. Lock J, Raat H, Duncan N, et al. Adherence to treatment in a Western European paediatric population with haemophilia: reliability and validity of the VERITAS-Pro scale. Haemophilia. 2014;20(5):616-623.

46. Armstrong EP, Malone DC, Krishnan S, Wessler MJ. Adherence to clotting factors among persons with hemophilia A or B. Hematology. 2015;20(3):148-153.
47. Haynes RB, Taylor DW, Sackett DL. Compliance in Health Care. Baltimore: Johns Hopkins University Press; 1979.

48. Llewellyn CD, Miners AH, Lee CA, Harrington C, Weinman JA. The illness perceptions and treatment beliefs of individuals with severe haemophilia and their role in adherence to home treatment. Psychol Health. 2003;18(2):185-200.

49. Tran DQ, Barry V, Antun A, Ribeiro M, Stein S, Kempton CL. Physician trust and depression influence adherence to factor replacement: a singlecentre cross-sectional study. Haemophilia. 2017;23(1):98-104.

50. Petrini P. Identifying and overcoming barriers to prophylaxis in the management of haemophilia. Haemophilia. 2007;13(Suppl 2):16-22.

51. Gue D, Squire S, McIntosh K, et al. Joining the patient on the path to customized prophylaxis: one hemophilia team explores the tools of engagement. J Multidiscip Healthc. 2015;8:527-534.

52. Bérubé S, Mouillard F, Amesse C, Sultan S. Motivational techniques to improve self-care in hemophilia: the need to support autonomy in children. BMC Pediatr. 2016;16:4.

53. Khair K, Meerabeau L, Gibson F. Self-management and skills acquisition in boys with haemophilia. Health Expect. 2015;18(5):1105-1113.

54. Breakey VR, Warias AV, Ignas DM, White M, Blanchette VS, Stinson JN. The value of usability testing for Internet-based adolescent selfmanagement interventions: "Managing Hemophilia Online". BMC Med Inform Decis Mak. 2013;13:113.

55. Breakey VR, Ignas DM, Warias AV, White M, Blanchette VS, Stinson JN. A pilot randomized control trial to evaluate the feasibility of an Internet-based self-management and transitional care program for youth with haemophilia. Haemophilia. 2014;20(6): 784-793.

56. MicroHealth. Learn more: key features. Available from: https://microhealth.org/pages/learn-more.html. Accessed February 5, 2015.

57. Schrijvers LH, Kars MC, Beijlevelt-van der Zande M, Peters M, Schuurmans MJ, Fischer K. Unravelling adherence to prophylaxis in haemophilia: a patients' perspective. Haemophilia. 2015;21(5): 612-621.

58. Brand B, Dunn S, Kulkarni R. Challenges in the management of haemophilia on transition from adolescence to adulthood. Eur J Haematol. 2015;95(81):30-35.

59. Quon D, Reding M, Guelcher C, et al. Unmet needs in the transition to adulthood: 18- to 30-year-old people with hemophilia. Am J Hematol. 2015;90(Suppl 2):S17-S22.

60. De Moerloose P, Urbancik W, van den Berg HM, Richards M. A survey of adherence to haemophilia therapy in six European countries: results and recommendations. Haemophilia. 2008;14(5):931-938.

61. Saxena K. Barriers and perceived limitations to early treatment of hemophilia. J Blood Med. 2013;4:49-56.

62. Ono O, Suzuki Y, Yosikawa K, et al. Assessment of haemophilia treatment practice pattern in Japan. Haemophilia. 2009;15(5):1032-1038.

63. Colombo GL, Di MS, Mancuso ME, Santagostino E. Cost-utility analysis of prophylaxis versus treatment on demand in severe hemophilia A. Clinicoecon Outcomes Res. 2011;3:55-61.

64. Farrugia A, Cassar J, Kimber MC, et al. Treatment for life for severe haemophilia A: a cost-utility model for prophylaxis vs. on-demand treatment. Haemophilia. 2013;19(4):e228-e238.

65. Globe DR, Curtis RG, Koerper MA. Utilization of care in haemophilia: a resource-based method for cost analysis from the Haemophilia Utilization Group Study (HUGS). Haemophilia. 2004;10(Suppl 1): 63-70.

66. Majumdar S, Ostrenga A, Latzman RD, et al. Pharmacoeconomic impact of obesity in severe haemophilia children on clotting factor prophylaxis in a single institution. Haemophilia. 2011;17(4):717-718.

67. Iowa Hemophilia Advisory Committee. Report to the governor and general assembly 2009. 2010. Available from: http://www.idph. state.ia.us/adper/common/pdf/legis/2009_hemophilia.pdf. Accessed February 4, 2015.

68. Tarantino MD, Ye X, Bergstrom F, Skorija K, Luo MP. The impact of the economic downturn and health care reform on treatment decisions for haemophilia A: patient, caregiver and health care provider perspectives. Haemophilia. 2013;19(1):51-58. 
69. Collins PW, Blanchette VS, Fischer K, et al. Break-through bleeding in relation to predicted factor VIII levels in patients receiving prophylactic treatment for severe hemophilia A. J Thromb Haemost. 2009; $7(3): 413-420$.

70. Fischer K, van der Bom JG, Prejs R, et al. Discontinuation of prophylactic therapy in severe haemophilia: incidence and effects on outcome. Haemophilia. 2001;7(6):544-550.

71. Duncan NA, Kronenberger WG, Krishnan S, Shapiro AD. Adherence to prophylactic treatment in hemophilia as measured using the VERITASPro and annual bleed rate (ABR). Value Health. 2014;17(3):A230.

72. McLaughlin JM, Witkop ML, Lambing A, Anderson TL, Munn J, Tortella B. Better adherence to prescribed treatment regimen is related to less chronic pain among adolescents and young adults with moderate or severe haemophilia. Haemophilia. 2014;20(4):506-512.

73. Iorio A, Krishnan S, Myren K, Lethagen S, McCormick N, Karner P. Modeling the impact of potential differences in real-wolrd [sic] adherence with extended-half-life vs. conventional factor VIII and IX on bleeding. Value Health. 2015;18(7):A660-A661.

74. Lindvall K, Colstrup L, Wollter IM, et al. Compliance with treatment and understanding of own disease in patients with severe and moderate haemophilia. Haemophilia. 2006;12(1):47-51.

75. Young G. From boy to man: recommendations for the transition process in haemophilia. Haemophilia. 2012;18(Suppl 5):27-32.

76. Fischer K, Valentino L, Ljung R, Blanchette V. Prophylaxis for severe haemophilia: clinical challenges in the absence as well as in the presence of inhibitors. Haemophilia. 2008;14(Suppl 3):196-201.

77. Miller TA. Health literacy and adherence to medical treatment in chronic and acute illness: a meta-analysis. Patient Educ Couns. 2016; 99(7):1079-1086.

78. Kardas P, Lewek P, Matyjasczczyk. Determinants of patient adherence: a review of systematic reviews. Front Pharmacol. 2013;4:91.
79. HemAware. Hemophilia summer camps. 2010. Available from: https:// hemaware.org/story/hemophilia-summer-camps. Accessed March 13, 2015 .

80. Hoffman JA, Cunningham JR, Suleh AJ, et al. Mobile direct observation treatment for tuberculosis patients: a technical feasibility pilot using mobile phones in Nairobi, Kenya. Am J Prev Med. 2010;39(1): 78-80.

81. Volpp KG, Loewenstein G, Troxel AB, et al. A test of financial incentives to improve warfarin adherence. BMC Health Serv Res. 2008; $8: 272$.

82. Wyrwich KW, Krishnan S, Poon JL, Auguste P, von Maltzahn R, Yu R. Health-related quality of life data changes from baseline using HaemA-QoL scores in the A-LONG clinical study of recombinant factor VIII Fc fusion protein. Haemophilia. 2014;20(Suppl 3):169.

83. Wyrwich KW, Krishnan S, Poon JL, Auguste P, von Maltzahn R, Yu R. Health-related quality of life data changes over time using Haem-AQoL scores in the B-LONG clinical study of recombinant factor IX Fc fusion protein. Haemophilia. 2014;20(Suppl 3):173.

84. Klamroth R, Quon DV, Kulkarni R, et al. Subject-reported changes in physical activity during the A-LONG study of recombinant factor VIII Fc fusion protein (rFVIIIFc) for severe haemophilia A. Haemophilia. 2015;21(Suppl 2):34.

85. Windyga J, Ragni M, Pasi KJ, et al. Subject-reported changes in physical activity during the B-LONG study of recombinant factor IX Fc fusion protein (rFIXFc) for severe haemophilia B. Haemophilia. 2015;21(Suppl 2):29.

86. Bosworth HB, Granger BB, Mendys P, et al. Medication adherence: a call for action. Am Heart J. 2011;162(3):412-424.
Patient Preference and Adherence

\section{Publish your work in this journal}

Patient Preference and Adherence is an international, peer-reviewed, open access journal that focuses on the growing importance of patient preference and adherence throughout the therapeutic continuum. Patient satisfaction, acceptability, quality of life, compliance, persistence and their role in developing new therapeutic modalities and compounds to optimize

\section{Dovepress}

clinical outcomes for existing disease states are major areas of interest for the journal. This journal has been accepted for indexing on PubMed Central. The manuscript management system is completely online and includes a very quick and fair peer-review system, which is all easy to use. Visit http://www. dovepress.com/testimonials.php to read real quotes from published authors. 